\title{
Simulation-based education for selected communication skills: exploring the perception of post-graduate dental students
}

\author{
Sharon Mascarenhas ${ }^{1}$, Manal Al-Halabi ${ }^{1}$, Farah Otaki', Mohamed Nasaif ${ }^{2}$ and Dave Davis ${ }^{1}$ \\ ${ }^{1}$ Mohammed Bin Rashid University of Medicine and Health Sciences, and ${ }^{2}$ Training and Development Center, \\ Ministry of Health and Prevention, Dubai, United Arab Emirates
}

Purpose: The role of simulation-based education (SBE) in enhancing communication has been established in the literature. To ensure achieving desired outcomes from SBE initiative, the individual learners, their experiences, and environments need to be considered. This study aimed at exploring the perception of post-graduate dental students regarding their participation in SBE sessions, around selected communication skills, designed in alignment with the assumptions of adult learning theory and steps of Kolb's experiential learning cycle.

Methods: This study utilized a qualitative design. Six focus-group sessions were conducted following the SBE sessions. The generated data was inductively investigated using a multi-staged participant-focused approach to thematic analysis, based upon constructivist epistemology. NVivo was utilized to facilitate text Fragments' coding and categorization.

Results: Forty-three post-graduate dental students participated. The analysis resulted in 16 categories spread across five sequential phases of the SBE experience. The "input" theme referred to the resources needed for the SBE process, and included three categories: facilities, personnel, and teaching materials. The second theme included steps of SBE "process": pre-brief, simulation, and debrief. The third, fourth, and fifth themes constituted the short- and longer-term results of the SBE intervention. The participants reported instant benefits on confidence in their expertise in communicating with patients and their guardians. Additionally, perceived effects on the empathy and professionalism were reported.

Conclusion: SBE, that is based upon adult and experiential learning theories, and developed after thorough consideration of the individual learners, and their experiences and learning environments, holds potential in enhancing communication skills among post-graduate dental students.

Key Words: Dental education, Learning, Communication, Dentistry

\section{Introduction}

Today, there is substantial evidence around the importance of communication in improving the quality of health care. It is proven that good interpersonal communication between medical professionals and patients leads to less burnout of medical professionals, improved doctor-patient relationships, heightened patient adherence to medical advices, better therapeutic outcomes, and increased satisfaction amongst patients [1]. Improved healthcare communication has also been
Received: September 24, 2020 • Revised: November 11, 2020 - Accepted: December 7, 2020 Corresponding Author: Manal Al-Halabi (https://orcid.org/0000-0001-9482-4614)

Hamdan Bin Mohammed College of Dental Medicine, Mohammed Bin Rashid University of Medicine and Health Sciences, PO Box 35701 Dubai, United Arab Emirates

Tel: +971.555510564 Fax:+971.43838937 email: Manal.Halabi@mbru.ac.ae
Korean J Med Educ 2021 Mar; 33(1): 11-25

https://doi.org/10.3946/kjme.2021.183

eISSN: 2005-7288

(C) The Korean Society of Medical Education. All rights reserved. This is an open-access article distributed under the terms of the Creative Commons Attribution Non-Commercial License (http:// creativecommons.org/licenses/by-nc/3.0/), which permits unrestricted non-commercial use, distribution, and reproduction in any medium, provided the original work is properly cited. 
associated with improvements in various objective and subjective health parameters, including: blood pressure control, and hemoglobin $\mathrm{A} 1 \mathrm{C}$ in diabetes [2].

Many medical and dental educators, around the globe, argue that communication is a core clinical skill, and hence, should not be an optional curricular component. For the most part, and when present, the training for communication skills is often in the form of lectures or passive learning, with very limited skills-based practice [3].

The use of clinical simulation involving simulated patients, as an experiential learning strategy, is widespread in medical education. In a systematic literature review to evaluate the effectiveness of educational interventions on healthcare professionals' situation awareness (SA), simulation-based education (SBE) turned out to be the most common learning and teaching modality, and in comparison with other modalities, it yielded better SA outcomes [4]. Another study showed that active learning of crisis resource management (CRM) using simulation, consisting of team problem-solving activities, resulted in improved CRM performance in comparison with that relying on didactic teaching only [5]. As for dental schools, in addition to the ubiquitous use of mannequins in preclinical dentistry, some programs have incorporated simulation in other areas, including the use of virtual and simulated patients [3].

It is established in the literature that to ensure effective practice-based learning, educators need to consider the learners, their experiences, and the overall learning environment [6]. Adult education is different from childhood education. The differences have led to two distinct educational approaches to learning and teaching: pedagogy, the teaching of children, and andragogy, the teaching of adults [6]. Accordingly, it is recommended for learning and development opportunities, targeting adults, to be based upon adult learning theory, where the learners are assumed to be self-directed and have the capacity to regulate themselves [7]. This theory is also based upon the premises that the learners, as adults, are intrinsically motivated to learn, have previously acquired knowledge that takes the form of mental models, and use analogical reasoning in learning and practice.

According to the Kolb's experiential learning theory, simulation offers a concrete hands-on experience in a safe environment [8]. Through guided reflections (feedback and debriefing), learners are supported in identifying gaps in their mental models and adapting accordingly. In addition, simulation provides the opportunity for active experimentation by allowing the learner to try-out new ideas immediately [9].

Previous studies found that simulations were especially useful for teaching interpersonal skills, including but not limited to communication (particularly when compared to didactic instructions) [10,11]. Very few of these studies, however, were regarding its application in postgraduate dental education, and none captured the perception of the students.

Given the importance of training for communication skills among dentists, along with the established effectiveness of experiential learning in this realm, The Mohammed Bin Rashid University of Medicine and Health Sciences (MBRU) Institute piloted, as part of its postgraduate dental programs, a simulation-based learning opportunity that aimed primarily at developing selected communication skills. The intervention was developed after thorough consideration of the individual learners, and their experiences and environments. It was designed and delivered in alignment with adult and experiential learning theories, where the learners were encouraged to reflect, and in turn adapt their mental model. This study aimed at exploring the perception of 
the post-graduate dental students regarding their participation in this SBE intervention to get in-depth insights into the value of basing such simulation activities on practice-based learning theories.

\section{Methods}

\section{Context}

This study was conducted at MBRU in Dubai, United Arab Emirates at Hamdan Bin Mohammed College of Dental Medicine (HBMCDM), which offers several dental postgraduate programs. As part of the programs, the students receive didactic teaching in general communication skills. With the intention of strengthening specific communication skills that are proven to be of importance to the respective specialties, HBMCDM decided to pilot an SBE opportunity across all the enrolled students. All the post-graduate dental students across all 3 years, and five specialties (prosthodontics, endodontics, oral surgery, pediatric dentistry, and orthodontics) were offered a briefing session about the value of $\mathrm{SBE}$ in teaching communication skills, and asked, by the director of the corresponding specialty, to take part in the respective $\mathrm{SBE}$ intervention as a complementary part of the curriculum.

\section{Implemented simulation-based education intervention}

\section{1) Description of the SBE intervention}

The SBE intervention revolved around training of dental students in selected communication skills, developed after thorough consideration of the learners, and their experiences and learning environments. The skills selected for this intervention included: communication during consent, breaking bad news, and

\begin{tabular}{cl}
\hline Table 1. Sample Schedule for a Simulation Session and Focus Group \\
\hline $\begin{array}{c}\text { Time } \\
\text { (min) }\end{array}$ & \multicolumn{1}{c}{ Activity } \\
\hline 10 & Introduction \\
& Outline of the session \\
& Signing confidentiality \\
& Safe container \\
35 & Scenario 1 \\
& Pre-briefing (5 min) \\
& Students provide consultation with simulated patient (15 min) \\
& Debriefing (15 min) \\
35 & Scenario 2 \\
& Pre-briefing (5 min) \\
& Students provide consultation with simulated patient (15 min) \\
& Debriefing (15 min) \\
35 & Scenario 3 \\
& Pre-briefing (5 min) \\
& Students provide consultation with simulated patient (15 min) \\
& Debriefing (15 min) \\
15 & Feedback and reflection \\
45 & Focus group discussion \\
\hline &
\end{tabular}

communication during an unexpected outcome. All the 43 students who were enrolled in the programs participated in this SBE intervention. The students, within each specialty, were divided into six groups, with six to eight participants per group.

Each group went through three 35-minute scenarios, which were conducted at the dental clinic (in-situ). The simulated patients were given a priori a detailed script of the simulated clinical scenarios, including possible responses and questions that could be asked. Each session commenced with introductions, describing the session details, discussing a safe container, and signing of confidentiality forms. Before the pre-briefing, the students were encouraged to interact with the simulated patients followed by the simulation and then the debriefing. The final 15 minutes were allocated to summarizing the session. Table 1 demonstrates the schedule of each of the six simulation sessions.

2) Data collection integral to the SBE intervention

Before the sessions, basic demographic data was 
collected, and immediately after the simulation sessions, the students completed a reflection form, and rated their own competence against the following variable: I feel competent to handle situations, similar to the ones I just experienced, in clinical practice. For the latter selfassessment, a Likert-type scale of 1 to 5 was used, with 1 representing "strongly disagree" all the way to 5 which indicated "strongly agree".

3) The SBE intervention's theoretical underpinnings

The learning and development opportunity, in alignment with Kolb's experiential learning theory, ensured offering the learners a concrete experience, followed by abstract conceptualization where the learners further develop their own mental models based on what they had acquired from the experience [12]. Moreover, the assumptions of the adult learning theory constituted the basis of this opportunity $[13,14]$. The adapted SBE and the complementary learning resources (e.g., pre-reading materials which included scientific papers and relevant policies from the Dubai Dental Hospital [DDH]) require capacity of self-directed learning and of regulating oneself. The students were expected to go over the DDH policies and procedures, and pre-course reading material although they were not formally requested to do so; this vital information was frequently alluded to during the intervention. Moreover, enrolling in the respective learning and development opportunity was voluntary, where the students were asked to take part in this intervention. The students were assumed to be intrinsically motivated to learn. The scenarios and associated interactions with the simulated patients in the SBE exercises were based on previously acquired knowledge and past learning experiences. Also, the debriefing session was designed in a way to maximize reflecting, offering the students sufficient space to explore, and reconsider prior knowledge and mental models, and capitalize upon them to further one's understanding of the subject matter.

\section{Research design and participants' recruit- ment}

This study utilized a qualitative participant-focused research design. A focus group session was conducted with each of the six groups of students across all the specialties. These focus group sessions took place right after the participants completed filling the reflection form after the SBE session, where one of the researchers (independent from the college) verbally invited the students to participate in the research study through joining the focus group session. The researcher assured the students that they have complete autonomy to choose whether, or not, to participate. This study was approved by the Institutional Review Board of MBRU (MBRUIRB-2018-016).

To ensure standardization across the focus group sessions, a protocol was used, which was designed in alignment with the Schon 1983 guidelines [15], adapted to match the intricacies of this investigation (Appendix 1). This protocol comprised of 13 open-ended questions, spread across four sections, aimed at capturing the students' perception of the differing modes of learning and teaching, and their suitability for acquiring communication skills, the SBE learning experience under investigation, the added value of developing communication skills for the participants' education and career trajectories, and wrapping-up the discussion.

\section{Data collection}

To ensure that the participants express themselves freely, the selected focus group facilitators were not members of the HBMCDM. This also helped in keeping any potential bias, due to conflict of interests, to a minimum. The focus groups sessions were facilitated by 
two researchers (D.D. and M.N.), who are trained in conducting participant-focused qualitative research. Moreover, those two researchers, were not involved, neither directly nor indirectly, in the SBE intervention under investigation. The research participants were requested to sign a consent form prior to the initiation of data collection. At the start of each session, the facilitators reassured the participants of the data confidentiality and anonymity, and built rapport with the participants, encouraging them to share their ideas and thoughts openly, even if they are divergent in nature, and to exchange thoughts and ideas among each other as the conversation unfolds. In addition, as per the requirements of the participant-focused qualitative research, the interviewers were mindful about withholding their ideas and opinions while conducting the sessions to avoid data contamination.

The generated data collection tool underwent two validation phases. Firstly, three experts in the transference of soft skills in medical education were contacted for the content validity. Secondly, the questions of the generated tool were discussed with six members of the University's community, who do not belong to the HBMCDM (two simulations educators, two faculty members, and two students) to assess the clarity, comprehensibility, and readability of the questions and the flow by which they are presented (i.e., face validity).

The audio recordings of the focus group sessions underwent verbatim transcription by another researcher (S.M.). The transcripts were revised by the same researcher while listening to the audio recording, again, to identify and edit any errors or omissions. Each participant was assigned a unique identification number.

\section{Data analysis}

The data analysis started after the completion of the data collection phase. The data was inductively in- vestigated using a participant-focused approach to thematic analysis by three researchers (S.M., M.A., and F.O.). The approach was iterative and based upon the constructivist epistemology. Consistency, concerning the underlying theories and assumptions, was assured throughout the study. In contrast to traditional scientific research, this interpretive (or interpretative) understanding process involves the ability to recognize and recreate the experiences of the participants. The goal of this approach is to understand the people, and their thoughts and ideas, and actions, rather than to find casual explanations [16]. This methodology assumes that we can describe what people think by listening and understanding what they say [17].

The process of analysis followed the six-step framework initially introduced by Braun and Clarke [18] in 2006. This multi-staged approach to thematic analysis is widespread and is encouraged in health professions education research [19]. NVivo software ver. 12.0 plus (QSR International Pty. Ltd., Chadstone, Australia) was used to code the data, and in turn facilitate the categorization of the identified text fragments.

The analysis process started with the three researchers familiarizing themselves with the data. As for the second step, the transcripts were reviewed while coding the text fragments that relate, directly or indirectly, to the research question. This kept going until no new information was observed in the datasets, and hence data saturation was attained.

This review led to the generation of categories of text fragments which set the stage for the researchers to work on step three. These categories underwent several rounds of reflections; the different ways by which these categories could relate to one another were identified. It became apparent to the researchers that the categories refer to differing phases of the SBE system. So, the researchers agreed to explore how the generated 
categories relate to the general system theory [20]. The general system theory can reveal the multidisciplinary nature of the phenomenon under investigation. It also enables the researchers to tap into the dynamics, and the relationship between micro- and macro-level of analyses, and to assimilate a holistic perception the natural and human worlds [21]. Accordingly, these categories were then fitted into the following sequential themes: input, process, output, outcome, and impact. All the themes and categories were then defined to complete stage five. This constituted the study's conceptual framework which guided the last step of the thematic analysis: reporting upon the findings.

With the intention of conducting a respondent validation, the informant feedback was obtained through a 2-hour discussion conducted with the participants after the completion of the data analysis and the generation of the study's conceptual framework. In the respective meeting, the participants were shown three PowerPoint Presentation slides that included the research questions followed by the conceptual framework, an explanation of the qualitative analysis, and a visual representation of the system theory, respectively. After showing the conceptual framework and explaining it verbally to them, the students were given the space to reflect upon the extent of resonance between their responses to the research questions and the conceptual framework. They agreed with all the identified codes and how they relate to one another.
Nevertheless, they found it challenging to understand the temporal differences between the variables identified within the output, outcome, and impact themes. This was not unexpected since the students had no previous knowledge regarding the systems' theory. Hence, after further explaining slides 2 and 3, they became more acquainted with the theory that guided the researchers in their analysis.

\section{Results}

All the students $(n=43)$ who took part in the SBE intervention voluntarily participated in the corresponding focus group sessions. Table 2 demonstrates the

$\overline{\text { Table 2. Demographic Characteristics of Participating Post-graduate }}$ Dental Students

\begin{tabular}{lc}
\hline \multicolumn{1}{c}{ Descriptor } & No. $(\%)$ \\
\hline Gender & \\
Male & $12(27.91)$ \\
Female & $31(72.09)$ \\
Specialty & \\
Pediatric dentistry & $11(25.58)$ \\
Orthodontics & $16(37.21)$ \\
Endodontics & $6(13.95)$ \\
Prosthodontics & $9(20.93)$ \\
Oral surgery & $1(2.33)$ \\
Years of experience in dentistry & \\
$0-5$ & $27(62.79)$ \\
$6-10$ & $14(32.56)$ \\
$11-15$ & $2(4.65)$ \\
\hline
\end{tabular}

Fig. 1. Thematic Analysis of the Study Results Representing Five Phases of a System

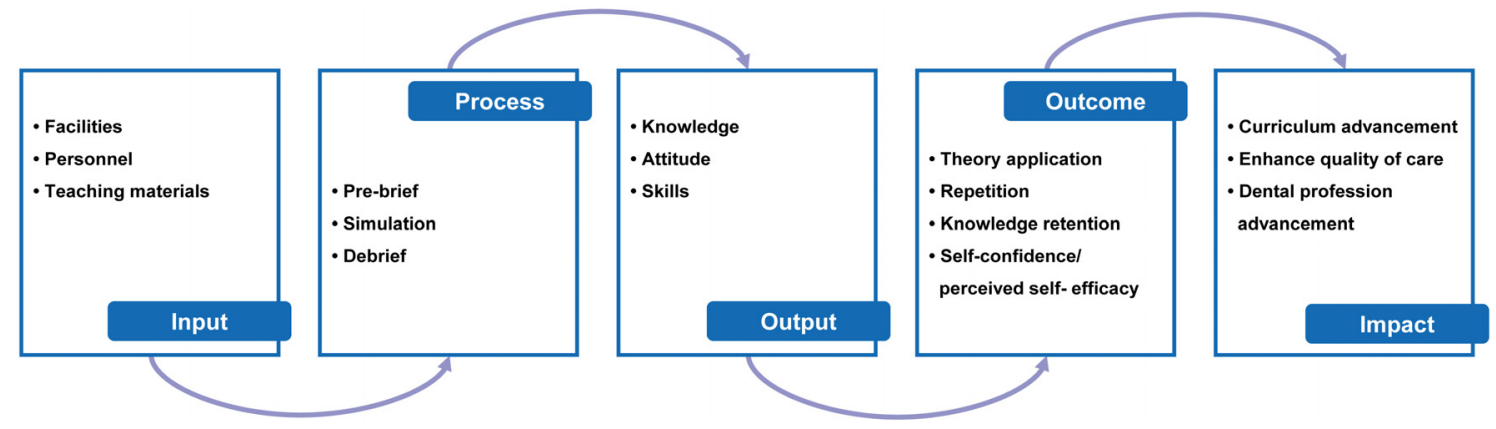


demographic characteristics of the postgraduate students participating in the SBE sessions and focus group meetings.

The post-intervention self-assessment showed that $19 \%$ of the students "strongly agree" that they are competent in handling similar situations in their clinical practice, $67 \%$ selected "agree", and only $14 \%$ were "neutral". None of the students selected "disagree" or "strongly disagree".

As illustrated in this study's conceptual framework, the thematic analysis resulted in 16 categories spread across the five phases of a system. This framework is demonstrated in Fig. 1.

\section{Input}

The "input" theme referred to the resources that are needed for the SBE process to occur, and it included three categories: facilities, personnel, and teaching materials.

\section{1) Facilities}

The facilities category covered all text segments that referred to the physical environment in which the SBE process took place (e.g., dental clinic, simulation laboratory, debriefing room, and meeting rooms). Below are two such exemplars:

40: "*.the environment was comfortable $\cdots$ "

42: " $\cdots$ it was very beneficial for us to have it in a real situation in the clinic we usually use daily..."

\section{2) Personnel}

As for the personnel category, it included all the text fragments that referred to the human resources needed for the SBE process to occur (e.g., simulation educator technologist, dental faculty, dental students, and simulated patients). For example, the students mentioned:

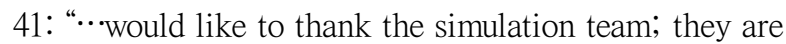
helpful and motivating..."

01: "*.it was good, the actors and the patients $\cdots$ "

\section{3) Teaching materials}

The last category within this theme was the "teaching materials". This category encapsulated text fragments that referred to relevant resources that complimented and in turn enriched the learning experience integral to the SBE process (e.g., prereading material, discussing research papers, and PowerPoint presentation on basic communication skills).

20: “...it was very good actually, not only good, very good because we had a prior session when we discussed some publications related to today's scenarios..."

39: “*videos, presentations and case scenarios will be a helpful way of learning..."

\section{Process}

The second theme that surfaced from the analysis was "process" which encapsulated all the text fragments that referred to steps of SBE, namely: pre-brief, simulation activity, and debrief. Each of these steps constituted a category under this theme.

\section{1) Pre-brief}

The pre-brief step was the orientation session held prior to the start of a simulation activity in which instructions or preparatory information was given to the participants. The purpose of the pre-briefing was to set the stage for a scenario and assist participants in achieving scenario objectives. Related to this realm, the participating students highlighted:

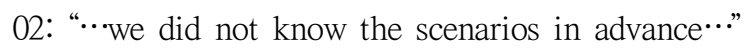

38: "* the environment was comfortable $\cdots$ " 


\section{2) Simulation activity}

The simulation step revolved around an array of structured activities that mimicked actual or potential situations in education and in clinical practice. The students were quite descriptive around this step of the process. Several students described the fidelity of the simulation:

36: “-.even though it is simulation, I personally felt as if I am dealing with a real mother who is concerned about her child...”

37: “.”the scenarios were relevant; they were real-life everyday situations that can happen with any dentist $\cdots \cdots$

A few of the students reflected upon the talents needed to put together such an SBE intervention:

20: " $\cdots$ there were different actors doing different scenarios. They knew the scenario well. They acted it out perfectly ..."

03: "‥I think it is very creative $\cdots$ "

Students also referred to the stress associated with the exercise:

01: "'*suddenly, you feel like your heart is pounding fast and you have to choose the right words, be calm, listen to whomever is in front of you, try to convince them about the treatment or the situation..."

35: “.”having professors there evaluating you was stressful $\cdots "$

04: “ $\cdots$ it was very stressful. I had to act and respond quickly and in a correct way and whatever you say or do will be evaluated..."

02: "...knowing that everyone is watching and evaluating you is stressful $\ldots$.

\section{3) Debrief}

The last category within this theme was the debrief step: a collaborative, reflective process within the simulation learning activity. The students seemed to appreciate the feedback, and the interactions and group learning that took place in this step.

34: " $\cdots$ today it was a good experience because we were able to get feedback from the supervisors as well as the simulated patient $\cdots$.

19: " $\cdots$ the feedback from the simulated patient was very Informative..."

03: " $\cdots$ we had enough time for discussion..."

\section{Output}

The output theme indicated the direct effects of the SBE process on the dental students.

\section{1) Knowledge}

To start with, the experience enabled the students to acquire knowledge:
18: " $\cdots$ these sessions prepare us for international examinations..$"$

33: " $\cdots$ these sessions added to our knowledge at the present time. I hope this will be helpful when we are dealing with a real-life situation..."

32: " $\cdots$ it really had added to our knowledge. The performance, everyone's inputs, and the supporting research papers..."

\section{2) Attitude}

The students also referred to changes in their attitude. They noticed new ways of thinking and feeling about, and relating to matters:

25: "...I really learnt that we need to show empathy no 
matter how simple we think the procedure is. We should always understand of the parents' feelings and how they respond to us in these situations $\cdots ”$

30: "..my take home message is to put myself in the shoes of the parent..."

21: “- I think simulation will improve some aspect of our personalities. Even shy students when confronted will start talking and break barriers $\cdots ”$

17: " $\cdots$ I think simulation and acting will improve some aspects in our personality. Some people are shy but when you come in front of people and start talking, doing things it'll break some barriers..."

21: "‥I think if you do an excellent root canal treatment without proper communication, the patients will not leave happy. If you do an average root canal treatment with proper communication, they will leave happy and satisfied..."

\section{3) Skills}

The last category within this theme was the skills, which referred to the acquired behaviors that the residents gained from the respective empirical experience:

16: “.”communication skills develop with clinical experience. You have to build it up..”

05: “-. for us breaking bad news was only cancer related. We realized extractions and cavities can be a big deal for parents $\cdots "$

\section{Outcome}

The fourth theme was the outcome of the SBE intervention. It relates to how the direct effects of the SBE process came together to affect the learning and teaching at the respective dental college.

\section{1) Theory application}

The first category within this theme related to the opportunity to apply theoretical knowledge acquired through the curriculum:

23: "'.no matter how much you read, unless you apply it, hands on, you will not get it or do it correctly..."

22: " $\cdots$ they emphasize what you learn in lectures $\cdots "$

06: "..this is the best way to learn communication skills..$"$

42: "...no matter how many lectures were taken, it is never like the practical experience..."

\section{2) Repetition}

Within the same theme, the value of learning through practicing and repetition surfaced at several points in the discussion:

15: "‥we need more such enriching sessions so we can practice more and properly learn certain skills..."

24: “...I think it is a useful learning opportunity to practice what we will eventually face in real life- we learn how to act professionally, then and there..."

14: “.”we will try to practice what we learnt today in communication with the patients, the more we practice the more we will benefit..."

\section{3) Knowledge retention}

Another category within this theme was knowledge retention, where the students highlighted that they perceive this opportunity as a platform to increase students' capacity to recall acquired information.

11: "...with interactive sessions, the things you learn stick in your head..."

25: " $\cdots$ It will stick in our mind when we practice it directly $\cdots "$ 
4) Self-confidence, and perceived self-efficacy, and professional identity as dentists

The last category within the outcome theme included self-confidence, perceived self-efficacy, and professional identity as dentists. This category included text fragments which related to the opportunity to increase the students' trust in their own ability to apply the acquired knowledge.

05: "‥I really believe it is beneficial because sometimes even if we know the information and how to deal with the situation, when you are put in a real situation it is different $\cdots$ you have no other option but to deal with it $\cdots ”$

13: " $\cdots$ it is better to face these situations in your training to learn from them rather than making mistakes after graduation and getting sued for these mistakes...”

07: “...It builds your confidence and gives you the skill of how to deal with the situation. Through simulation, you experience the emotions that are related to the situation, and become more confident to apply the knowledge and skills..."

\section{Impact}

Finally, the fifth theme referred to the long-term "impact". This theme related to the long-term effects of the SBE process on the participants. Within this theme, the following three categories surfaced: curriculum advancement, enhanced quality of care, and dental profession advancement.

\section{1) Curriculum advancement}

The curriculum advancement referred to how the SBE intervention constituted an opportunity to strengthen the dental curriculum:

07: “ $\cdots$ The curriculum needs to include more of these kinds of learning opportunities, where we are put in situations to exercise and get feedback regarding our communication skills, breaking bad news, reporting mistakes to the patients and parents, and interacting with colleagues from other departments..."

12: " $\cdots$ I really feel that communication in our practice is very important especially as pediatric dentists because we are not only dealing with patients, we deal with patients and the parents, so it is very important that we communicate well $\cdots$ "

13: " $\cdots$ this course should be a permanent part of the ethics course because it reinforces the whole content...

\section{2) Enhanced quality of care}

The Enhancement of quality of care referred to how the SBE intervention constituted an opportunity to improve the patient experience and in turn outcomes of care.

12: “.”scenarios help teach us how to professionally deal with issues and how not to point out other colleagues' mistakes next to patients...”

37: " $\cdots$ I learnt that the patient or the parent perceives matters in a different way than us as experts in the subject matter perceive it. I might see a simple extraction while they see it as something drastic..."

\section{3) Dental profession advancement}

Advancement of the dental profession referred to how the SBE intervention constituted an opportunity to add value to the dental profession.

10: " $\cdots I$ really feel that communication in our practice is very important and especially as pediatric dentists..."

08: " $\cdots$ as a dentist, you need to have good communication skills..."

09: " $\cdots$ the better communication skills you have, the better and easier your professional life would be..." 


\section{Discussion}

The findings of this study showed that the participating students valued the SBE intervention. They perceived a myriad of benefits of such an SBE intervention; some of which occurred instantly, and others that they expect will require some time to materialize. Adult learning theory and Kolb's experiential learning cycle enabled focusing on the learners, and their experiences and learning environments. All of this constituted a firm foundation for using simulation to improve communication, and in turn patient outcomes and safety. By choosing to perceive the analyzed qualitative data from a system perspective, the researchers showed that the added value of such an SBE intervention can be divided into three layers: instant output, longer-term outcome, and in turn impact.

Many of the participating students indicated that the scenarios felt "real". The importance of communication in improving clinical practice outcomes has been demonstrated in the literature [1]. By possessing effective communication skills, dental practitioners play an active role in facilitating the required interactions with their colleagues and the patients. The quality of relationships between health professionals, including dentists, and their patients has a significant impact on the respective patients' well-being and health outcomes [10].

The simulation, as reported by the students, had a direct effect on their knowledge, skills, and attitudes, around the subject matter. These perceptions are in line with findings of a 2017 scoping review of communication skills training in dental education [22].

The SBE intervention affected the students' attitude and not solely their behaviors. This uncovers a value of using simulation that is less likely to be achieved via didactic "one-way" teaching methods [23]. According to behavior change theories [24], by targeting an underlying attitude, the resulting change in behavior will be more sustainable.

The perceived attitude changes reported by the participants included but were not limited to overcoming shyness which is expected to lead to better communication with patients and better empathy. Apparently, SBE greatly impacts empathy among training students [25], and the students participating in this study frequently alluded to this matter.

Among the interesting findings of this study was one where most of the participating students seemed to believe that the SBE intervention developed their confidence in handling situations similar to the scenarios that they experienced as part of this SBE intervention. Accordingly, this learning and development opportunity raised the participating students perceived self-efficacy.

The participating students also appreciated the fact that this SBE intervention enabled them to apply the theory that they have been acquiring as part the respective post-graduate dental programs that they are enrolled in. Relevantly, they referred to the privilege of getting to practice certain skills and how entailed repetition maximizes knowledge retention. Along the same lines, Broder et al. [26] illustrated how the effect of a communication program, using simulated patients, which aimed primarily at enhancing interpersonal skills of undergraduate dental students, extended beyond the immediate output. These skills were proven to be retained with the students' as they are progressing academically, and in turn transferred from the classroom setting to their clinical practice [26].

In line with previously conducted studies, the students also reflected upon the potential long-term impact of such an SBE intervention where they believed it would improve the academic curriculum and ultimately the quality of care provided by the students currently under 
training $[22,25,26]$. The use of simulation to compliment the teaching of theoretical knowledge was reported to enhance the reliability of the curriculum [27].

There seems to be an interesting relationship between the SBE experience and the students' level of stress. Many students indicated how they experienced stress during the simulation session because they were aware that they were under observation and will be judged based on their performance. A few studies report that the physiological stress associated with observation and judgement might decreased the ability to perform $[3,4]$. Other studies, such as that by Macdougall et al. [28], reported that the participants in their study although feeling stressed during the SBE due to observation, did not report any negative effects on confidence levels. The insights of the students suggested that the more the observation and associated judgement were unobtrusive, the more comfortable the students felt. In a systematic review of observer roles that optimize learning, O’ Regan et al. [29] concluded that the value their students attach to observer roles appear contingent on the observer's role clarity, use of observer tools, and inclusion of observers' perspectives in the debrief. Hence, proper institutionalization of such SBE interventions and their effective integration into the curriculum will maximize the benefits and decrease the level of stress experienced by the students. On the other hand, some participating students reported that going through SBE can decrease their stress levels on the long run when they are faced with similar situations, in their clinical practice. This is in agreement with another study that showed SBE induced stress to decline with repetition [30]. From this perspective, it will be interesting for future studies, investigating the effect of SBE, to longitudinally assess the changes of stress levels across time before, during, and after conducting the SBE intervention. This will inform health professionals' educators on how best to position the SBE intervention and frame the messages around it to maximize learning.

This research work can be characterized by several limitations that are worth mentioning. The case-study design adapted for this research work enabled a thorough understanding of the phenomenon under investigation, yet it limited the generalizability of the results. Moreover, the heavy reliance on qualitative data enabled the investigators to capture worthwhile insights yet allowed for a lot of subjectivity. In addition, the participating students might have been inclined to answer in a positive way to avoid undermining the effort that has been put to undergo this SBE opportunity. Finally, other than the self-assessment, the study captured no performance data.

To increase the generalizability of the results, we suggest for future studies to compare several SBE interventions across differing institutions, perhaps in a longitudinal design. Moreover, the subjectivity inherent in the qualitative analysis can be buffered if complimented with the analysis of quantitative data, representing the perception of the students and/or their preceptors. For that matter, future studies can aim to be based on mixed method approaches that triangulate data from differing sources. The positive impression developed by the students along with the results of the self-assessment can imply that the SBE intervention is effective. Yet, it would be recommended for future studies to define a more structured manner to assess the extent to which the SBE intervention met its pre-set objectives.

In conclusion, this SBE intervention had a perceived positive effect on the attitude of the students. This particularly applies to increased empathy, professionalism, and the development of the professional identity. Moreover, using the general system theory in this study proved to be useful for structuring and analyzing qualitative data in SBE research. From that 
perspective, the study also showed that the students developed an understanding of how such SBE interventions will affect them in the long run. This starts with enhancing their learning experience and the teaching offered to them, and later in strengthening the curriculum, and ultimately the respective healthcare profession. Accordingly, SBE, that is based upon adult and experiential learning theories, and that is developed after thorough consideration of the learners, their experiences and learning environments, holds potential in developing interpersonal skills among students and other medical students.

\section{ORCID:}

Sharon Mascarenhas: https://orcid.org/0000-0003-1005-3838;

Manal Al-Halabi: https://orcid.org/0000-0001-9482-4614;

Farah Otaki: https://orcid.org/0000-0002-8944-4948;

Mohamed Nasaif: https://orcid.org/0000-0003-1972-2989;

Dave Davis: https://orcid.org/0000-0001-5198-4466

Acknowledgements: The authors would like to acknowledge Dr Eman Al Nuaimi, Dr Anas Al Salami, Meghana Sudhir, Safeeja Abdul Rahuman, Richard Ormonde, and Abimon Mundakkalveedu for their valuable contributions in running the $\mathrm{SBE}$ and in transcribing the focus groups.

Funding: The authors declare no specific funding was assigned to this project.

Conflicts of interest: No potential conflict of interest relevant to this article was reported.

Author contributions: SM, MA, DD, and MN contributed to the conception or design of the work, data collection, data analysis and interpretation, drafting the article, critical revision of the article, and final approval of the version to be published. FO contributed to data analysis and interpretation, drafting the article, critical revision of the article, and final approval of the version to be published.

\section{References}

1. Woelber JP, Deimling D, Langenbach D, Ratka-Krüger P. The importance of teaching communication in dental education: a survey amongst dentists, students and patients. Eur J Dent Educ. 2012;16(1):e200-e204.

2. Gilligan T, Coyle N, Frankel RM, et al. Patient-clinician communication: American Society of Clinical Oncology consensus guideline. J Clin Oncol. 2017;35(31):36183632.

3. McKenzie CT, Tilashalski KR, Peterson DT, White ML. Effectiveness of standardized patient simulations in teaching clinical communication skills to dental students. J Dent Educ. 2017;81(10):1179-1186.

4. Walshe NC, Crowley CM, O'Brien S, Browne JP, Hegarty JM. Educational interventions to enhance situation awareness: a systematic review and meta-analysis. Simul Healthc. 2019;14(6):398-408.

5. Saravana-Bawan BB, Fulton C, Riley B, et al. Evaluating best methods for crisis resource management education: didactic teaching or noncontextual active learning. Simul Healthc. 2019;14(6):366-371

6. Knowles MS. Application in continuing education for the health professions: chapter five of "andragogy in action". Mobius. 1985;5(2):80-100.

7. Jones F, Passos-Neto CE, Braghiroli OF. Simulation in medical education: brief history and methodology. Princ Pract Clin Res. 2015;1(2):56-63.

8. Stocker M, Burmester M, Allen M. Optimisation of simulated team training through the application of learning theories: a debate for a conceptual framework. BMC Med Educ. 2014;14:69.

9. Zigmont JJ, Kappus LJ, Sudikoff SN. Theoretical foundations of learning through simulation. Semin Perinatol. 2011;35(2):47-51.

10. Gelis A, Cervello S, Rey R, et al. Peer role-play for 
Sharon Mascarenhas, et al : Perception of postgraduate dental students about communication simulation

training communication skills in medical students: a systematic review. Simul Healthc. 2020;15(2):106-111.

11. Natt N, Starr SR, Reed DA, Park YS, Dyrbye LN, Leep Hunderfund AN. High-value, cost-conscious communication skills in undergraduate medical education: validity evidence for scores derived from two standardized patient scenarios. Simul Healthc. 2018;13(5):316-323.

12. Poore JA, Cullen DL, Schaar GL. Simulation-based interprofessional education guided by Kolb's experiential learning theory. Clin Simul Nurs. 2014;10(5):e241-e247.

13. Merriam SB. Adult learning theory for the twenty-first century. New Dir Adult Contin Educ. 2008;(119):93-98.

14. Shannon S. Adult learning and CME. Lancet. 2003; 361 (9353):266.

15. Schon DA. The reflective practitioner: how professionals think in action. New York, USA: Basic Books; 1983.

16. Cortazzi, M. Narrative analysis. London, UK: Falmer Press; 1993.

17. Cortazzi M, Jin L, Wall D, Cavendish S. Sharing learning through narrative communication. Int J Lang Commun Disord. 2001;36 Suppl:252-257.

18. Braun V, Clarke V. Using thematic analysis in psychology. Qual Res Psychol. 2006;3(2):77-101.

19. Kiger ME, Varpio L. Thematic analysis of qualitative data: AMEE guide no. 131. Med Teach. 2020;42(8): 846-854.

20. Chen D, Stroup W. General system theory: toward a conceptual framework for science and technology education for all. J Sci Educ Technol. 1993;2(3): 447-459.

21. Chua C. Perception of quality in higher education. Paper presented at: Proceedings of the Australian Universities Quality Forum 2004: Quality in a Time of Change; July
7-9, 2004; Adelaide, Australia.

22. Ayn C, Robinson L, Nason A, Lovas J. Determining recommendations for improvement of communication skills training in dental education: a scoping review. J Dent Educ. 2017;81(4):479-488.

23. Dye CA. Persuasion, simulation and attitude change. Int J Soc Psychiatry. 1981;27(2):154-160.

24. Weller J, Frengley R, Torrie J, Webster CS, Tomlinson $\mathrm{S}$, Henderson $\mathrm{K}$. Change in attitudes and performance of critical care teams after a multi-disciplinary simulationbased intervention. Int J Med Educ. 2012;3:124-131.

25. Bearman M, Palermo C, Allen LM, Williams B. Learning empathy through simulation: a systematic literature review. Simul Healthc. 2015;10(5):308-319.

26. Broder HL, Janal M, Mitnick DM, Rodriguez JY, Sischo L. Communication skills in dental students: new data regarding retention and generalization of training effects. J Dent Educ. 2015;79(8):940-948.

27. Nolan T, Loubier C. Relating instructor feedback and student reception in the clinical environment. Radiol Technol. 2018;89(3):238-256.

28. Macdougall L, Martin R, McCallum I, Grogan E. Simulation and stress: acceptable to students and not confidence-busting. Clin Teach. 2013;10(1):38-41.

29. O'Regan S, Molloy E, Watterson L, Nestel D. Observer roles that optimise learning in healthcare simulation education: a systematic review. Adv Simul (Lond). 2016;1:4.

30. Ghazali DA, Breque C, Sosner P, et al. Stress response in the daily lives of simulation repeaters: a randomized controlled trial assessing stress evolution over one year of repetitive immersive simulations. PLoS One. 2019;14(7): $\mathrm{e} 0220111$. 
Sharon Mascarenhas, et al : Perception of postgraduate dental students about communication simulation

\section{Appendix 1. Focus Group Protocol}

Focus group protocol: simulation-based education for selected communication skills: exploring the perception of post-graduate dental students

Section 1: Differing modes of learning and teaching, and their suitability for acquiring communication skills

1. Please reflect upon the differing modes of learning and teaching.

2. What is your favourite mode of learning and teaching (e.g., lectures, online, and flipped classroom), and why?

3. What do you think is the best mode of learning and teaching for acquiring communication skills?

Section 2: The simulation-based education (SBE) learning experience under investigation

4. How was your SBE learning experience today?

5. Please describe your views on learning and teaching communication skills through SBE.

6. What, in your opinion, are the advantages/ benefits of using SBE to teach communication skills?

7. What, in your opinion, are the disadvantages/ pitfalls of using SBE to teach communication skills?

Section 3: The added value of developing communication skills among post-graduate dental students

8. Please describe the added value of teaching communication skills in the post-graduate dental curriculum.

9. Please describe the importance of proficiency of communication skills in dental practise.

10. Please describe your perception of the usefulness of what you acquired today as you proceed in the postgraduate program, that you are currently enrolled in, and (later) in your clinical practice?

11. How will you use what you acquired today?

Section 4: Wrap-up

12. What is your take-home message post simulation session?

13. Please share anything else that you would like to say about today's learning activity. 